\title{
Unified Model Reference Adaptive Attitude Control of a Satellite in Presence of Uncertain Parameters: Design and Implementation
}

\author{
Farhad Fani Saberi \\ Amirkabir University of \\ Technology \\ Space Science and \\ Technology Institute \\ Tehran, Iran
}

\author{
Sadegh Ahmadi Dastgerdi \\ Islamic Azad University of \\ South Tehran Branch \\ Department of Control \\ Engineering \\ Tehran, Iran
}

\author{
Mehdi Zandieh \\ Islamic Azad University of \\ Boroujerd \\ Department of Control \\ Engineering \\ Boroujerd, Iran
}

\begin{abstract}
In this paper, a discrete-time model reference adaptive attitude control algorithm (MRAC) will be designed based on unified approach for a three-axis stabilized satellite. In this algorithm, environmental disturbances and nonlinear dynamic terms will be estimated as a time-varying unknown parameter. In this method, nonlinear dynamic equation of satellite is rewritten as a linear model with uncertain parameters as the main novel idea. Therefore, MRAC algorithm is designed for the linear model in the presence of uncertain parameters, and then it will be applied to the nonlinear model of the satellite in presence of uncertain or unknown parameters. The proposed method is capable of simultaneous tracking and regulation. The designed algorithm will be implemented in software in the loop test bed with the use of ARM microcontroller in real time mode in order to evaluation and verification of its performance.
\end{abstract}

\section{Keywords}

Attitude control; Model reference adaptive control (MRAC); Satellite; Software in the loop; Unified Approach; ARM microcontroller.

\section{INTRODUCTION}

Designing a proper algorithm to control a satellite for achieving various missions, constitutes a large portion of the activities of the designers in this area. In this regard, various control methods of satellite from classic to advanced have been designed [1,2]. Due to unknown environmental conditions and uncertainty parameters of satellite dynamic model, classical controllers are not so appropriate for such conditions. To overcome this problem, robust controllers such as sliding mode controllers have been proposed [3]. However, robust controllers don't have appropriate performance in presence of parameter changes. This problem has been solved by applying adaptive controllers. In adaptive control, the use of projection function is one of the common methods that estimation parameters are guaranteed to be bounded in the presence of uncertainty [4]. In [5], an adaptive controller has been designed for a rigid spacecraft in the presence of external disturbances and moment of inertia matrix uncertainties; in this method, a sliding mode controller has been designed without considering any constraints and then its performance will be improved by applying an adaptive control algorithm. In this method, the robustness and the high speed convergence of parameters estimations have been guaranteed without considering of actuators saturation constraints. In [6], design and implementation of various model reference adaptive controllers have been designed in discrete time mode. Accordingly, Retrospective Cost Adaptive Control (RCAC) method has been used for satellite attitude control in [7].Meanwhile, a method called "unified" approach has been initially introduced in [8]. In [2], a supervisory control algorithm has been offered for the satellite attitude control in the presence of inertia matrix uncertainty based on the unified approach. The considerable point in this method is no need for the information of uncertainties' bounds. Numerical results indicate the effectiveness of this algorithm in the presence of disturbances.

In this paper, a discrete-time model reference adaptive attitude control algorithm (MRAC) will be designed based on unified approach for a three-axis stabilized satellite. In this algorithm, environmental disturbances and nonlinear dynamic terms will be estimated as a time-varying unknown parameter. In this algorithm, to eliminate the effect of uncertainties and unmodeled dynamics, two approaches have been proposed: 1Use of an uncertain time varying parameter which will be estimated using recursive least squares error method. 2- Use of output estimation error. Finally, the proposed control algorithm will be implemented in software in the loop test bed with the use of ARM microcontroller in real time mode. In the following, in section 2, satellite dynamic equations will be introduced. In section 3, adaptive control will be designed for the satellite based on the unified approach. In section 4, software in the loop test bed will be provided. In section 5, the designed algorithm will be simulated and implemented in software in the loop test bed and in section 6, the conclusions will be presented.

\section{SATELLITE EQUATIONS OF MOTION}

Based on the Euler's equation and Newton's third law, the dynamic equation of a satellite motion can be written as [9]:

$\mathrm{I} \dot{\omega}=\mathrm{T}-\omega \times \mathrm{H}$

Where $I=\operatorname{diag}\left[\begin{array}{lll}I_{x} & I_{y} & I_{z}\end{array}\right]$ is the moments of inertia of the satellite, $\omega=\left[\begin{array}{lll}\omega_{x} & \omega_{y} & \omega_{z}\end{array}\right]^{T}$ is satellite angular rate vector of the satellite body relative to the inertial coordinate system and $H$ is angular momentum vector where:

$H=I \omega$ 
$T=\left[\begin{array}{lll}T_{x} & T_{y} & T_{z}\end{array}\right]^{T}$ is the total torques applied on the satellite consists of control torques $T_{c}$, external disturbance torques $T_{d}$ and the Earth gravity torques $T_{g}$ as follow:

$T=T_{c}+T_{d}+T_{g}$

Satellite kinematic equation can be represented as follows [9]:

$\int \omega_{x}=\dot{\phi}-\dot{\psi} \sin (\theta)-\omega_{0} \cos (\theta) \sin (\psi)$

$\left\{\omega_{y}=\dot{\theta} \cos (\phi)+\dot{\psi} \cos (\theta) \sin (\phi)-\omega_{0}(\cos (\phi) \cos (\psi)+\sin (\phi) \sin (\theta) \sin (\psi))\right.$

$\omega_{z}=\dot{\psi} \cos (\theta) \cos (\phi)-\dot{\theta} \sin (\phi)-\omega_{0}(-\sin (\phi) \cos (\psi)+\cos (\phi) \sin (\theta) \sin (\psi))$

Where $\phi, \theta$ and $\psi$ (roll, pitch, and yaw, respectively) are the Euler angles; and $\omega_{0}$ is orbit angular rate.

\section{PRINCIPALS OF MRAC UNIFIED APPROACH FOR TRACKING AND REGULATION}

In order to design unified MRAC approach, it is necessary to use discrete linear time equations of the system. Consider a discrete linear time-invariant plant described by [8]:

$y_{p}(k)=\frac{q^{-t d} B\left(\mathrm{q}^{-1}\right)}{A\left(\mathrm{q}^{-1}\right)} u(k)$

$t d>0, y_{p}(0) \neq 0$

where

$$
\begin{aligned}
& B\left(q^{-1}\right)=b_{0}+b_{1} q^{-1}+\ldots+b_{n_{B}} q^{-n_{B}} \quad, \quad b 0 \neq 0 \\
& A\left(\mathrm{q}^{-1}\right)=1+a_{1} q^{-1}+a_{2} q^{-2}+\ldots+a_{n_{A}} q^{-n_{A}}
\end{aligned}
$$

$\left\{q^{-1}\right\}$ is the backward shift operator. $\mathrm{y}_{\mathrm{p}}(\mathrm{k}), u(k)$ and $t d$ are output, input and system time delay, respectively. $B\left(\mathrm{q}^{-1}\right)$ and $A\left(\mathrm{q}^{-1}\right)$ are the polynomials of the numerator and denominator of the discrete-time transfer function. The objectives of the proposed control are as follow:

(i) The control should be such that in tracking, the output of the process satisfies the equation (8) [8].

$\mathrm{C}_{1}\left(\mathrm{q}^{-1}\right) \mathrm{y}_{\mathrm{p}}(\mathrm{k})=\mathrm{q}^{-\mathrm{td}} \mathrm{D}\left(\mathrm{q}^{-1}\right) \mathrm{r}(\mathrm{k})$

where $C_{1}\left(\mathrm{q}^{-1}\right), D\left(\mathrm{q}^{-1}\right)$ are polynomials in $\left\{q^{-1}\right\}, C_{1}\left(\mathrm{q}^{-1}\right)$ is asymptotically stable and $r(\mathrm{k})$ is a bounded reference sequence.

(ii) The control should be such that in regulation $(r(k) \equiv 0)$, an initial disturbance $\left(y_{p}(0) \neq 0\right)$ is eliminated with the dynamics defined by (9) [8]

$\mathrm{C}_{2}\left(\mathrm{q}^{-1}\right) \mathrm{y}_{\mathrm{p}}(\mathrm{k}+\mathrm{td})=0, \mathrm{k} \geq 0$

Where $\mathrm{C}_{2}\left(\mathrm{q}^{-1}\right)$ is an asymptotic stable polynomial as equation (10).

$$
\mathrm{C}_{2}\left(\mathrm{q}^{-1}\right)=1+\mu_{1} q^{-1}+\mu_{2} q^{-2}+\ldots+\mu_{n} q^{-n c_{2}}
$$

A solution is obtained by using an explicit reference model given by

$$
\mathrm{C}_{1}\left(\mathrm{q}^{-1}\right) \mathrm{y}_{\mathrm{m}}(\mathrm{k})=\mathrm{q}^{-\mathrm{td}} \mathrm{D}\left(\mathrm{q}^{-1}\right) \mathrm{r}(\mathrm{k})
$$

Where $\mathrm{y}_{\mathrm{m}}(\mathrm{k})$ is the bounded reference model output. The error function is defined as

$\mathrm{e}(\mathrm{k})=\mathrm{y}_{\mathrm{p}}(\mathrm{k})-\mathrm{y}_{\mathrm{m}}(\mathrm{k})$

It is clear that the objectives of the control are accomplished if the following equation holds

$\mathrm{C}_{2}\left(\mathrm{q}^{-1}\right) \mathrm{e}(\mathrm{k}+\mathrm{td})=0 \quad \mathrm{k}>0$

Using the identity

$C_{2}\left(q^{-1}\right)=A\left(q^{-1}\right) S\left(q^{-1}\right)+q^{-t d} R\left(q^{-1}\right)$

where

$$
\begin{aligned}
& S\left(q^{-1}\right)=1+s_{1} q^{-1}+s_{2} q^{-2}+\ldots+s_{n_{S}} q^{-n_{S}} \\
& R\left(\mathrm{q}^{-1}\right)=r_{0}+r_{1} q^{-1}+r_{2} q^{-2}+\ldots+r_{n_{R}} q^{-n_{R}}
\end{aligned}
$$

It has been shown [8] that the preceding identity has a unique solution and $n_{S}=t d-1$ and $n_{R}=\max \left(n_{A}-1, n c_{2}-t d\right)$ Equation (13) can be written as

$$
\begin{aligned}
\mathrm{C}_{2}\left(\mathrm{q}^{-1}\right) \mathrm{e}(\mathrm{k}+\mathrm{td}) & =B\left(q^{-1}\right) S\left(q^{-1}\right) u(\mathrm{k})+R\left(q^{-1}\right) \mathrm{y}_{\mathrm{p}}(\mathrm{k})-C_{2}\left(q^{-1}\right) \mathrm{y}_{\mathrm{m}}(\mathrm{k}-t d) \\
& =b_{0} u(\mathrm{k}) \Theta_{0}^{T} \Phi_{0}(\mathrm{k})-C_{2}\left(q^{-1}\right) \mathrm{y}_{\mathrm{m}}(\mathrm{k}-t d) \\
& =\Theta^{T} \Phi(\mathrm{k})-C_{2}\left(q^{-1}\right) \mathrm{y}_{\mathrm{m}}(\mathrm{k}-t d)
\end{aligned}
$$

Where:

$$
\begin{aligned}
& \Phi_{0}^{T}(\mathrm{k})=\left[u(\mathrm{k}-1), \ldots, u\left(\mathrm{k}-t d-n_{B}+1\right), \mathrm{y}_{\mathrm{p}}(\mathrm{k}), \ldots, \mathrm{y}_{\mathrm{p}}\left(\mathrm{k}-n_{R}\right)\right] \\
& \Theta_{0}^{T}=\left[b_{0} s_{1}+b_{1}, b_{0} s_{2}+b_{1} s_{1}+b_{2}, \ldots, b_{n_{B}} s_{t d-1}, r_{0}, \ldots, r_{n_{R}}\right] \\
& \Phi^{T}(\mathrm{k})=\left[u(\mathrm{k}) ; \Phi_{0}^{T}(\mathrm{k})\right] \\
& \Theta^{T}=\left[b_{0} ; \Theta_{0}^{T}\right]
\end{aligned}
$$

Equating the right-hand side of equation (16) with zero, the control objective of (13) is achieved with the control law

$$
\mathrm{u}(\mathrm{k})=\frac{1}{b_{0}}\left[\mathrm{C}_{2}\left(\mathrm{q}^{-1}\right) \mathrm{y}_{\mathrm{m}}(\mathrm{k}+t d)-R\left(q^{-1}\right) \mathrm{y}(\mathrm{k})-B_{S}\left(q^{-1}\right) u(\mathrm{k})\right]
$$

Where:

$$
B_{S}\left(q^{-1}\right)=B\left(q^{-1}\right) S\left(q^{-1}\right)-b_{0}
$$

or equivalently

$$
u(\mathrm{k})=\frac{1}{b_{0}}\left[\mathrm{C}_{2}\left(\mathrm{q}^{-1}\right) \mathrm{y}_{\mathrm{m}}(\mathrm{k}+t d)-\Theta_{0}^{T} \Phi_{0}(\mathrm{k})\right]
$$

For a plant with unknown parameters, recursive least squares error algorithm is used to estimate them. Therefore estimated output will be computed as follows:

$\hat{y}(\mathrm{k})=\mathrm{P}(\mathrm{k}) \hat{\vartheta}(\mathrm{k})$

It is assumed that " $\wedge$ " represents the estimation parameters. In equation $(24), \hat{y}(\mathrm{k}), \hat{\vartheta}(\mathrm{k})$ and $\mathrm{P}(\mathrm{k})$ represent the estimated outputs, estimated parameters and regression vectors respectively, that are defined according to equations (25) and (26).

$$
\begin{aligned}
\hat{\vartheta}(\mathrm{k})=\left[\hat{\mathrm{a}}_{1}(\mathrm{k}), \hat{\mathrm{a}}_{2}(\mathrm{k}), \ldots, \hat{\mathrm{a}}_{n_{A}}(\mathrm{k}), \hat{\mathrm{b}}_{0}(\mathrm{k}), \hat{\mathrm{b}}_{1}(\mathrm{k}), \ldots, \hat{\mathrm{b}}_{n_{B}}(\mathrm{k})\right]^{T} \\
\mathrm{P}(k)=\left[-y_{p}(\mathrm{k}-1),-y_{p}(\mathrm{k}-2), \ldots,-y_{p}\left(\mathrm{k}-n_{A}\right),\right. \\
\left.u(\mathrm{k}-1), u(\mathrm{k}-2), \ldots, u\left(\mathrm{k}-n_{B}\right)\right]
\end{aligned}
$$

The algorithm for recursive least squares error is described in equations (27) - (30) [6].

1. Compute the estimation error $\varepsilon(\mathrm{k})$ :

$\varepsilon(\mathrm{k})=\mathrm{y}_{\mathrm{p}}(\mathrm{k})-\hat{y}(\mathrm{k})$ 
2. Compute following equation:

$\mathrm{G}(\mathrm{k})=\frac{\mathrm{F}(\mathrm{k}-1) \mathrm{P}(\mathrm{k})}{\lambda+\mathrm{P}^{\mathrm{T}}(\mathrm{k}) \mathrm{F}(\mathrm{k}-1) \mathrm{P}(\mathrm{k})}$

3. Update parameter $\mathrm{F}$ :

$\mathrm{F}(\mathrm{k})=\frac{1}{\lambda}\left[\mathrm{I}-\mathrm{G}(\mathrm{k}) \mathrm{P}^{\mathrm{T}}(\mathrm{k})\right] \mathrm{F}(\mathrm{k}-1)$

4. Update Estimation of unknown parameter:

$\hat{\vartheta}(\mathrm{k})=\hat{\vartheta}(\mathrm{k}-1)+\mathrm{G}(\mathrm{k}) \varepsilon(\mathrm{k})$

$\lambda$ is the forgetting factor. The value for forgetting factor selected by a designer usually ranges from 0.98 to 0.995 [8]. The stability of estimation recursive algorithm of the system parameters and the stability of control algorithm are proven in [6] and [9].

\subsection{Attitude Control Algorithm of Satellite \\ Based on Unified MRAC Approach}

In this section, a discrete-time model reference adaptive attitude control algorithm (MRAC) will be designed based on unified approach for a three-axis stabilized satellite in presence of the axes coupling effect, un-modeled dynamic and the external disturbances. Therefore attitude dynamic equations should be rewritten as equation (5). Thus, attitude dynamic equation of the satellite (Eq. (1)) linearized as below:

$$
\left\{\begin{array}{l}
\ddot{\phi}=\frac{T_{x}-4 \omega_{0}^{2}\left(I_{y}-I_{z}\right) \phi}{I_{x}}+d_{1} \\
\ddot{\theta}=\frac{T_{y}-3 \omega_{0}^{2}\left(I_{x}-I_{z}\right) \theta}{I_{y}}+d_{2} \\
\ddot{\psi}=\frac{T_{z}-\omega_{0}^{2}\left(I_{y}-I_{x}\right) \psi}{I_{z}}+d_{3}
\end{array}\right.
$$

Where $d_{1}, d_{2}$ and $d_{3}$ are variables which represents the nonlinear terms corresponding to axes coupling effect and environment disturbances.

The discrete time of linear dynamic equation (31) can be described as below for each axis.

$$
\begin{aligned}
& y_{p i}(\mathrm{k})=\frac{q^{-t d} B_{i}\left(q^{-1}\right)}{A_{i}\left(q^{-1}\right)} u_{i}(k)+d_{i}{ }^{\prime} \\
& t d>0, y_{p i}(0) \neq 0, \quad \mathrm{i}=1,2,3
\end{aligned}
$$

Where:

$$
\begin{aligned}
& y_{p_{1}}(k)=\phi(k), y_{p_{2}}(k)=\theta(k), y_{p_{3}}(k)=\psi(k) \\
& u_{1}(k)=T_{x}(k), u_{2}(k)=T_{y}(k), u_{3}(k)=T_{z}(k)
\end{aligned}
$$

The discrete time of linear dynamic equation (31) can be written in the form of equation (32) as below

$$
\begin{aligned}
& B_{i}\left(q^{-1}\right)=b_{0 i}+b_{1 i} q^{-1} \\
& A_{i}\left(\mathrm{q}^{-1}\right)=1+a_{l i} q^{-1}+a_{2 i} q^{-2}
\end{aligned}
$$

The nominal coefficients of numerators $\left(B_{i}\left(q^{-1}\right)\right)$ and denominators $\left(A_{i}\left(q^{-1}\right)\right)$ in equation (32) described as below. Where:

For $\phi(\mathrm{k})$ :

$$
\phi:\left\{\begin{array}{l}
a_{1 \mathrm{i}}=-2 \cosh \left(2 T_{S}\left(-\omega_{0}^{2} \frac{I_{y}-I_{z}}{I_{x}}\right)^{\frac{1}{2}}\right), \quad a_{2 i}=1 \\
-\left[\cosh \left(2 T_{S}\left(-\omega_{0}^{2} \frac{I_{y}-I_{z}}{I_{x}}\right)^{\frac{1}{2}}\right)-1\right] \\
b_{0 i}=b_{1 \mathrm{i}}=\frac{\left[\omega_{0}^{2}\left(I_{y}-I_{z}\right)\right.}{}
\end{array}\right.
$$

For $\theta(\mathrm{k})$ :

$$
\theta:\left\{\begin{array}{c}
a_{1 \mathrm{i}}=-2 \cosh \left(T_{S}\left(-3 \omega_{0}^{2} \frac{I_{x}-I_{z}}{I_{y}}\right)^{\frac{1}{2}}\right), \quad a_{2 \mathrm{i}}=1 \\
-\left[\cosh \left(T_{S}\left(-3 \omega_{0}^{2} \frac{I_{x}-I_{z}}{I_{y}}\right)^{\frac{1}{2}}\right)-1\right] \\
b_{0 i}=b_{1 \mathrm{i}}=\frac{\left[\omega_{0}^{2}\left(I_{x}-I_{z}\right)\right.}{}
\end{array}\right.
$$

For $\psi(\mathrm{k})$ :

$$
\psi:\left\{\begin{array}{c}
a_{1 \mathrm{i}}=-2 \cosh \left(T_{S}\left(-\omega_{0}^{2} \frac{I_{y}-I_{x}}{I_{z}}\right)^{\frac{1}{2}}\right) \quad a_{2 \mathrm{i}}=1 \\
b_{0 \mathrm{i}}=b_{1 \mathrm{i}}=\frac{-\left[\cosh \left(T_{S}\left(-\omega_{0}^{2} \frac{I_{y}-I_{x}}{I_{z}}\right)^{\frac{1}{2}}\right)-1\right]}{\omega_{0}^{2}\left(I_{y}-I_{x}\right)}
\end{array}\right.
$$

$\mathrm{d}_{i}^{\prime}(\mathrm{k})$ is a time-varying parameter corresponding to environmental disturbances and nonlinear dynamic terms which is described as follow:

$d_{i}^{\prime}(\mathrm{k})=\frac{\alpha_{i} z^{-2}+\alpha_{i} z^{-1}}{z^{-2}+\beta_{i} z^{-1}-1} d_{i}(\mathrm{k})$

In equation (40) the nominal $\alpha_{i}$ and $\beta_{i}$ are defined as below:

For $\phi(\mathrm{k})$ :

$$
\phi:\left\{\begin{array}{l}
\alpha_{i}=\frac{-I_{x}\left[\cosh \left(T_{S}\left(-4 \omega_{0}^{2} \frac{I_{y}-I_{z}}{I_{x}}\right)^{\frac{1}{2}}\right)-1\right]}{4 \omega_{0}^{2}\left(I_{y}-I_{z}\right)} \\
\beta_{\mathrm{i}}=-2 \cosh \left(T_{S}\left(-4 \omega_{0}^{2} \frac{I_{y}-I_{z}}{I_{x}}\right)^{\frac{1}{2}}\right)
\end{array}\right.
$$

For $\theta(\mathrm{k})$ :

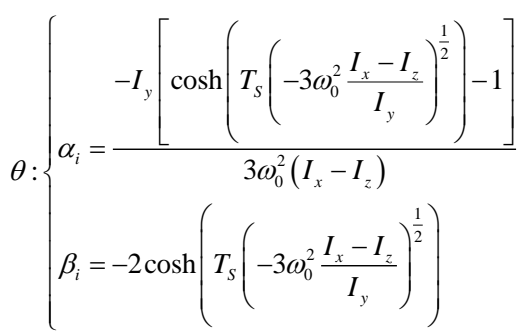


For $\psi(\mathrm{k})$ :

$$
\psi:\left\{\begin{array}{l}
\alpha_{\mathrm{i}}=\frac{-I_{z}\left[\cosh \left(T_{S}\left(-\omega_{0}^{2} \frac{I_{y}-I_{x}}{I_{z}}\right)^{\frac{1}{2}}\right)-1\right]}{\omega_{0}^{2}\left(I_{y}-I_{x}\right)} \\
\beta_{\mathrm{i}}=-2 \cosh \left(T_{S}\left(-\omega_{0}^{2} \frac{I_{y}-I_{x}}{I_{z}}\right)^{\frac{1}{2}}\right)
\end{array}\right.
$$

In equations (37) - (43) $T_{S}$ is sampling time. In the proposed MRAC method, two approaches will be proposed to estimate the time-varying parameter corresponding to environmental disturbances and nonlinear dynamic terms $\mathrm{d}_{i}^{\prime}(\mathrm{k})$ ' which will be considered as a time-varying unknown parameter.

\section{Approach 1:}

According to Equations (25), (26) and (32), estimation parameters, and regression vectors of dynamic equation of satellite can be written as equations (44) and (45) for each axis.

$$
\begin{aligned}
& \hat{\vartheta}_{i}(\mathrm{k})=\left[\begin{array}{lllll}
\hat{\mathrm{a}}_{1 \mathrm{i}}(\mathrm{k}) & \hat{\mathrm{a}}_{2 \mathrm{i}}(\mathrm{k}) & \hat{\mathrm{b}}_{0 \mathrm{i}}(\mathrm{k}) & \hat{\mathrm{b}}_{1 \mathrm{i}}(\mathrm{k}) & \hat{\mathrm{d}}_{\mathrm{i}}^{\prime}(\mathrm{k})
\end{array}\right]^{\mathrm{T}} \\
& \mathrm{P}_{i}(k)=\left[-y_{p i}(\mathrm{k}-1),-y_{p i}(\mathrm{k}-2), u_{i}(\mathrm{k}-1), u_{i}(\mathrm{k}-2), 1\right]
\end{aligned}
$$

Then by using equations (23), (44) and (45), the control law for each axis will be determined as follows:

$$
\begin{aligned}
\mathrm{u}_{\mathrm{i}}(\mathrm{k})= & \frac{1}{\hat{b}_{0 i}}\left[\mathrm{C}_{2}\left(\mathrm{q}^{-1}\right) \mathrm{y}_{\mathrm{mi}}(\mathrm{k}+t d)-\mathrm{C}_{2}\left(\mathrm{q}^{-1}\right) \hat{d}_{i}^{\prime}(\mathrm{k})-\hat{b}_{1 i} u_{i}(\mathrm{k}-1)\right. \\
& \left.-\left(\mu_{1}-\hat{a}_{1 i}\right) \mathrm{y}_{p i}(\mathrm{k})-\left(\mu_{2}-\hat{a}_{2 i}\right) \mathrm{y}_{p i}(\mathrm{k}-1)\right]
\end{aligned}
$$

The block diagram of this control algorithm is shown in Figure 1.

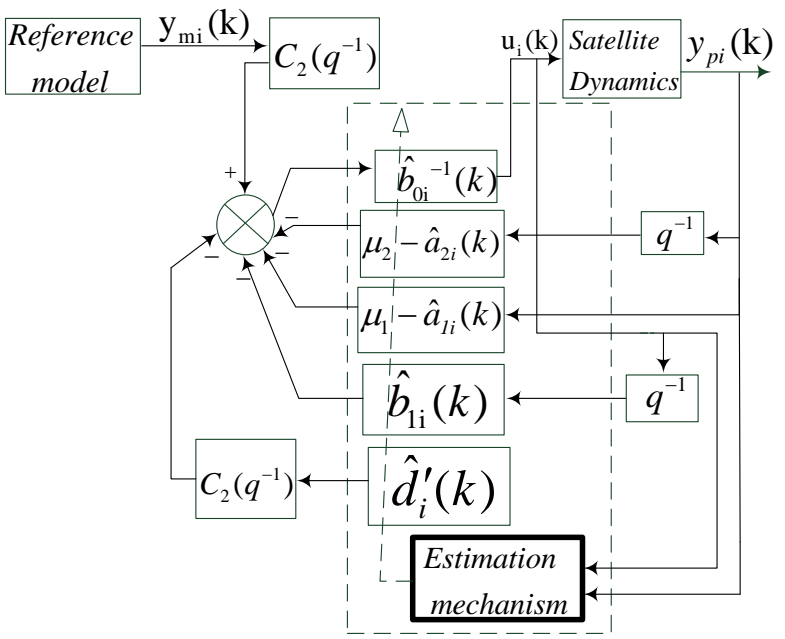

Fig 1: control algorithm block diagram (Approach 1)

\section{Approach 2:}

In this approach the parameter corresponding to environmental disturbances and nonlinear dynamic terms $\mathrm{d}_{i}^{\prime}(\mathrm{k})$ will be compensated using of estimation error $\varepsilon_{i}(\mathrm{k})$ Therefore the estimation parameters and the regressions vectors are defined as below:

$$
\begin{aligned}
& \hat{\vartheta}_{i}(\mathrm{k})=\left[\begin{array}{llll}
\hat{\mathrm{a}}_{\mathrm{li}}(\mathrm{k}) & \hat{\mathrm{a}}_{2 \mathrm{i}}(\mathrm{k}) & \hat{\mathrm{b}}_{0 \mathrm{i}}(\mathrm{k}) & \hat{\mathrm{b}}_{1 \mathrm{i}}(\mathrm{k})
\end{array}\right]^{\mathrm{T}} \\
& \mathrm{P}_{i}(\mathrm{k})=\left[\begin{array}{llll}
-\mathrm{y}_{\mathrm{pi}}(\mathrm{k}-1) & -\mathrm{y}_{\mathrm{pi}}(\mathrm{k}-2) & \mathrm{u}_{\mathrm{i}}(\mathrm{k}-1) & \mathrm{u}_{\mathrm{i}}(\mathrm{k}-2)
\end{array}\right]
\end{aligned}
$$

According to equation (27) it is clear that:

$$
\mathrm{y}_{\mathrm{pi}}(\mathrm{k})=\varepsilon_{i}(\mathrm{k})+\hat{y}_{i}(\mathrm{k})
$$

Now, by substituting equation (49) into equation (13) and using equations (27) - (30), the control law for each axis will be calculated as follow:

$$
\begin{aligned}
\mathrm{u}_{\mathrm{i}}(\mathrm{k})= & \frac{1}{\mathrm{~b}_{0 \mathrm{i}}}\left[\mathrm{C}_{2}\left(\mathrm{q}^{-1}\right) \mathrm{y}_{\mathrm{mi}}(\mathrm{k}+t d)+\mathrm{C}_{2}\left(\mathrm{q}^{-1}\right) \varepsilon_{i}(\mathrm{k})-\hat{b}_{\mathrm{1i}} \mathrm{u}_{i}(\mathrm{k}-1)\right. \\
& \left.-\left(\mu_{1}-\hat{a}_{\mathrm{ii}}\right) \mathrm{y}_{\mathrm{pi}}(\mathrm{k})-\left(\mu_{2}-\hat{a}_{2 \mathrm{i}}\right) \mathrm{y}_{\mathrm{pi}}(\mathrm{k}-1)\right]
\end{aligned}
$$

The block diagram of this control algorithm is shown in Figure 2 .

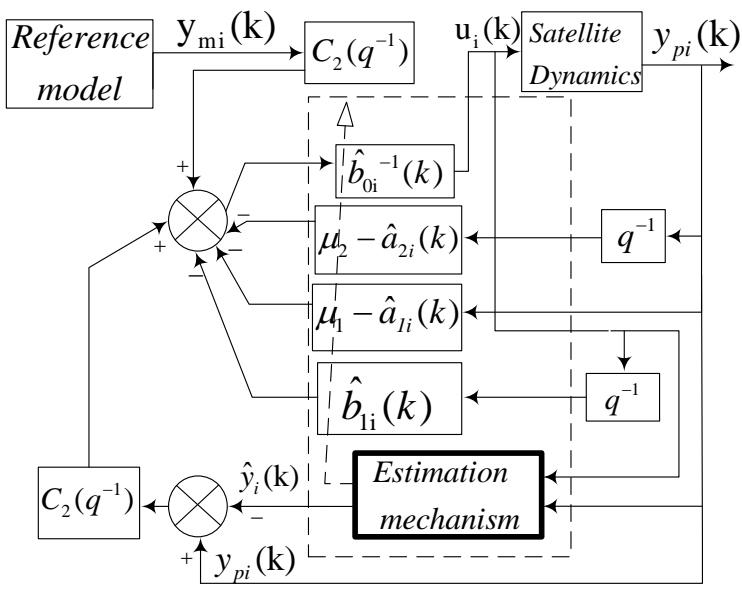

Fig 2: control algorithm block diagram (Approach 2)

In the next section, the two proposed approaches will be implemented in software in the loop test bed with the use of ARM microcontroller in real time mode in order to evaluation and verification of its performance.

\section{SOFTWARE IN THE LOOP TEST BED}

It's necessary to ensure the accurate performance of a satellite attitude control system before launch. One of the most important satellite test beds are simulators. In these test beds, the operating conditions of the tested subsystems are simulated and then the performance of the subsystems will be evaluated. A simulator of satellite attitude was made in 1959 in NASA Research Center [10]. California Polytechnic state University has been provided a $10 \mathrm{~kg}$ simulator with 2-3 degrees accuracy [11]. Also, in Lawrence Livermore International Laboratory, a simulator table with four degrees of freedom and in NASA's Marshall Space Flight Center, a simulator table with six degrees of freedom has been provided [12].

However, these test beds are complex with too hardware equipment which is too expensive. Therefore, it seems necessary to design and provide an appropriate test bed with low cost and high flexibility for the implementation of various control algorithms. In this paper, a test bed for evaluation of the control algorithm in real-time mode has been made using the RTW toolbox of MATLAB software which will be called software in the loop test bed so on $[13,14]$.

Configuration of the test bed contains three main parts including: simulator computer, on-board electronics using ARM type 32 bit microcontroller and an interface circuit for exchanging data between simulator computer and on-board electronics using RS232 serial port. 
The tasks of simulator computer can be expressed as: 1) modeling of orbital motion of satellite, rotational motion of satellite, environmental disturbances and actuators and sensors dynamics. 2) Providing a graphical convenient user interface for monitoring system performance.

Figure 3, shows the block diagram of the designed software in the loop test bed [3].

As is clear in Figure 3, the attitude information of the satellite using the sensors model will be sent to the electronic control section through the serial port. In the electronic control section, based on the received data such as angular velocity and satellite attitude, the desired control torque according to the designed control law, will be calculated and will be sent to the monitoring section and simulator computer through the serial port. Then by applying this torque to the dynamic system model in the simulator computer, the satellite attitude will be changed and then the new data will be sent to the monitoring section again. This loop continues in real time mode and the performance of the designed control algorithm will be evaluated. In Figure 4, the components of the software in the loop test bed has been shown.

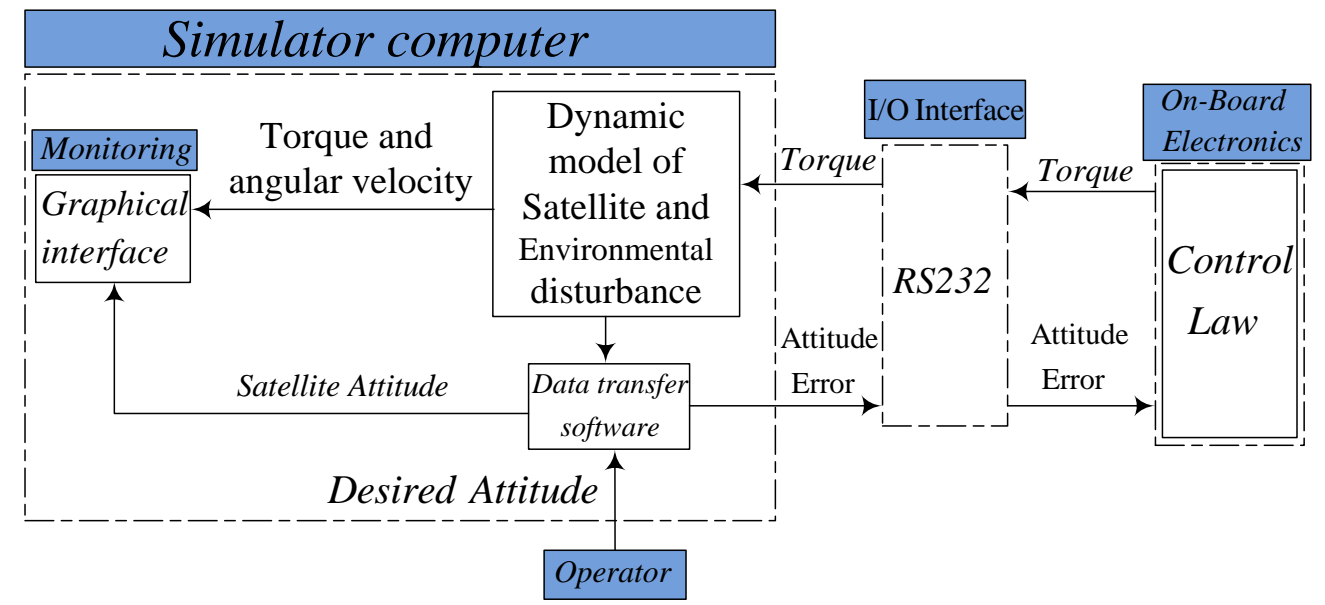

Figure 3: Block diagram of the software in the loop test bed

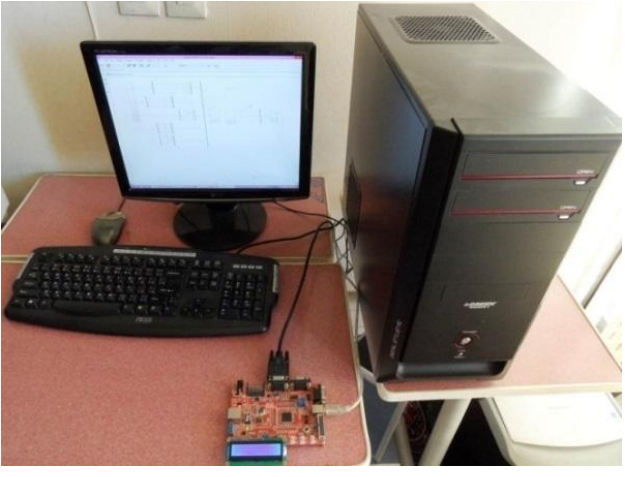

Fig 4: software in the loop test bed components

\section{Simulation and implementation}

In this section, the proposed MRAC algorithms based on unified approach (equations (46) and (50)) will be simulated and implemented in the software in the loop test bed in a realtime situation and the results will be investigated. Then the results of the software in the loop (SIL) tests for designed control algorithms are presented to demonstrate the capabilities of the mentioned algorithm in a real-time situation. The specifications of the satellite have been shown in Table 1 [15].

Table 1. Satellite attributes [15]

\begin{tabular}{|c|c|}
\hline$I_{y}=3.04 \mathrm{kgm}^{2}$ & $I_{z}=3.09 \mathrm{kgm}^{2}$ \\
\hline$I_{x}=2.13 \mathrm{kgm}^{2}$ & $h=600 \mathrm{~km}$ \\
\hline
\end{tabular}

$$
\left\{\begin{array}{l}
\phi_{0}=10^{\circ}, \quad \theta_{0}=-10^{\circ}, \quad \psi_{0}=10^{\circ} \\
\omega_{x}(0)=0.352 \frac{\mathrm{rad}}{\mathrm{sec}}, \quad \omega_{y}(0)=0.351 \frac{\mathrm{rad}}{\mathrm{sec}}, \quad \omega_{z}(0)=0.248 \frac{\mathrm{rad}}{\mathrm{sec}}
\end{array}\right.
$$

In these simulations, the satellite attitude determination data is extracted directly from simulation model and sampling time of the control loop has been considered 0.5 seconds. Therefore, the nominal polynomials of $B_{i}\left(\mathrm{q}^{-1}\right)$ and $A_{i}\left(\mathrm{q}^{-1}\right)$ in equations (41),(42) and (43) will be computed as below:

$$
\phi:\left\{\begin{array}{c}
\mathrm{B}_{1}\left(\mathrm{q}^{-1}\right)=0.0586+0.0586 \mathrm{q}^{-1} \\
\mathrm{~A}_{1}\left(\mathrm{q}^{-1}\right)=1-2 \mathrm{q}^{-1}+\mathrm{q}^{-2}
\end{array}\right.
$$

$\theta:\left\{\begin{array}{c}\mathrm{B}_{2}\left(\mathrm{q}^{-1}\right)=0.0411+0.0411 \mathrm{q}^{-1} \\ \mathrm{~A}_{2}\left(\mathrm{q}^{-1}\right)=1-2 \mathrm{q}^{-1}+\mathrm{q}^{-2}\end{array}\right.$

$\psi:\left\{\begin{array}{c}\mathrm{B}_{3}\left(\mathrm{q}^{-1}\right)=0.0404+0.0404 \mathrm{q}^{-1} \\ \mathrm{~A}_{3}\left(\mathrm{q}^{-1}\right)=1-2 \mathrm{q}^{-1}+\mathrm{q}^{-2}\end{array}\right.$

By considering the dynamic model of the satellite, the order of the $C_{2}\left(\mathrm{q}^{-1}\right)$ polynomial is two. The poles of this polynomial have been considered in $\left[\begin{array}{ll}0.001 & 0.001\end{array}\right]$. Thus we will have:

$\mathrm{C}_{2}\left(\mathrm{q}^{-1}\right)=1-0.002 \mathrm{q}^{-1}+10^{-6} \mathrm{q}^{-2}$

In the implementation of designed control algorithm, according to Table 2, 60 bytes should be sent to the electronic board and 12 bytes should be received through each sampling time. Thus, a serial port with the rate of sending and receiving 115200 bits per second has been configured. Therefore, the required sampling time will be calculated as below:

$\mathrm{T}_{\text {Data Transmit }}=\frac{72 \times 8}{115200}=0.005 \mathrm{sec}$ 
However, the required time for processing the control algorithms is 0.34 seconds. Thus, the minimum sampling time should be considered greater than 0.3405 seconds. So, in the following results the sampling time has been considered 0.5 seconds.

Table 2. The information attributes of the data sending and receiving from the electronic board

\begin{tabular}{|c|c|c|c|}
\hline & \multicolumn{2}{|c|}{ Data name } & Data volume \\
\hline \multirow{4}{*}{$\begin{array}{l}\text { Data sent to the } \\
\text { electronic board }\end{array}$} & \multirow{2}{*}{$\begin{array}{l}\text { desired } \\
\text { attitude }\end{array}$} & Present data & 12 bytes \\
\hline & & Past data & 24 bytes \\
\hline & \multirow{2}{*}{$\begin{array}{l}\text { Satellite } \\
\text { attitude }\end{array}$} & Present data & 12 bytes \\
\hline & & Past data & 12 bytes \\
\hline \multirow{3}{*}{$\begin{array}{l}\text { Data received } \\
\text { from the } \\
\text { electronic board }\end{array}$} & \multicolumn{2}{|c|}{ Roll control torque } & 4 bytes \\
\hline & \multicolumn{2}{|c|}{ Pitch control torque } & 4 bytes \\
\hline & \multicolumn{2}{|c|}{ Yaw control torque } & 4 bytes \\
\hline
\end{tabular}

In this case, we have considered a time delay equal to the one sampling time between the simulator computer and electronic board for data transferring. In other words, when the data are sent to the electronic board, the control law will be calculated and applied to the dynamic model of satellite in the next sampling time. This time delay should be considered in the modeling and designing of the control algorithm.

In the following simulations, the roll angle change from -25 to +25 degrees, the pitch angle change from -20 to +20 degrees and yaw axis will be regulated to zero. The forgetting factor in the estimation algorithm has been considered as 0.995 . The results from the simulation using the first approach (equation (46)) are shown in Figures (5) - (7).

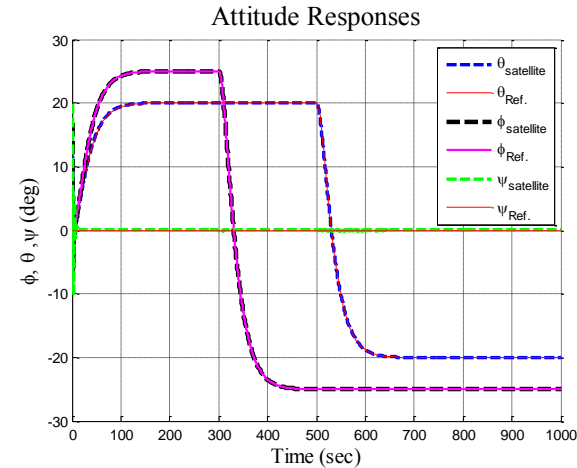

Fig 5: roll, pitch and yaw angle (first approach)

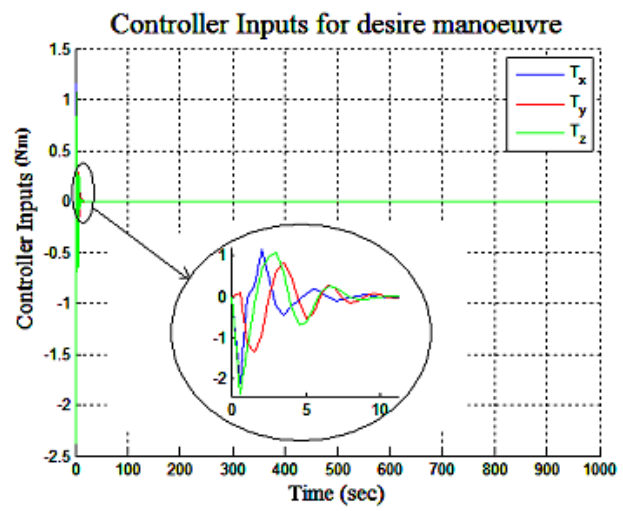

Fig 6: control torques (first approach)

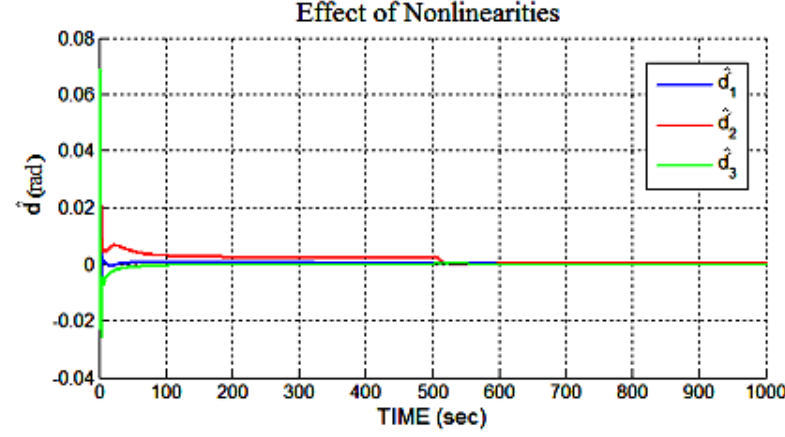

Fig 7: Nonlinearities estimation $\hat{d}_{i}^{\prime}$ (first approach)

In Figures (8) - (10), the results using the second approach are shown.

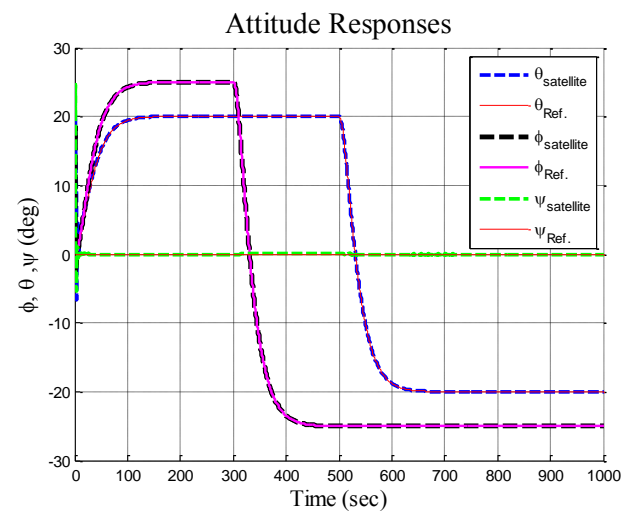

Fig 8: roll, pitch and yaw angles (second approach)

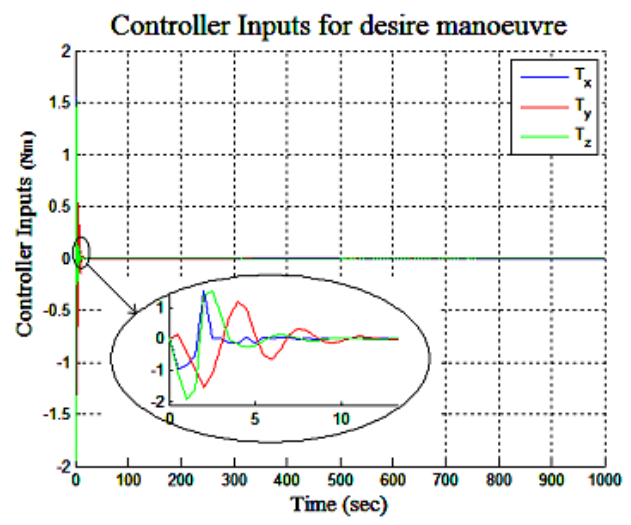

Fig 9: control torques (second approach)

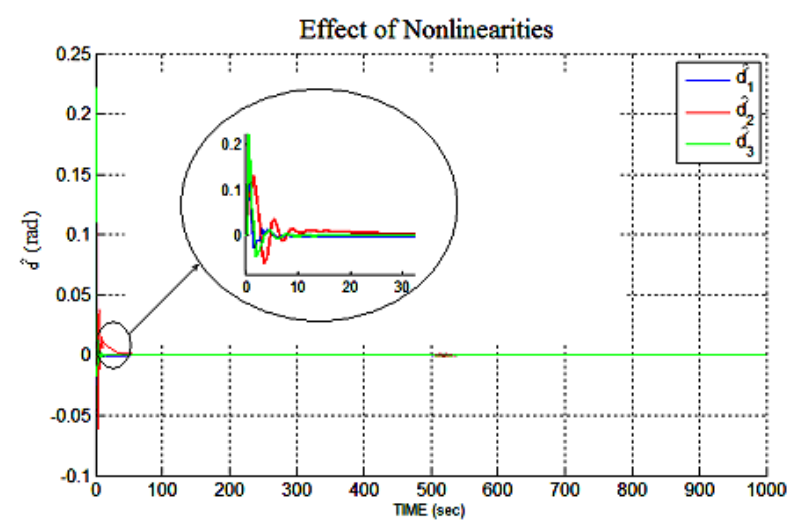

Fig 10: Nonlinearities estimation $\hat{d}_{i}^{\prime}$ (second approach) 
According to figures (5) - (10), it can be concluded that the designed algorithms work effectively in tracking and regulation. Figures (7) and (10) show that the estimation convergence speeds of uncertainty parameter $\hat{d}_{i}^{\prime}$ by using the second approach is higher than the first approach.

The implementation results of the proposed control algorithms in software in the loop test bed are shown in Figures (11) - (14).

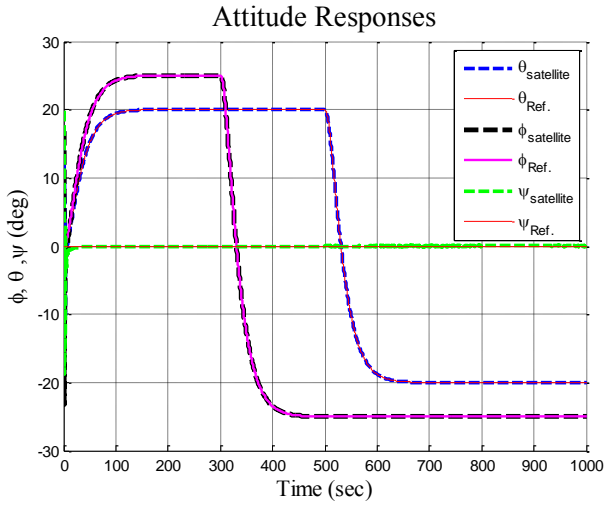

Fig 11: roll, pitch and yaw angles (first approach implementation)

Controller Inputs for desire manoeuvre

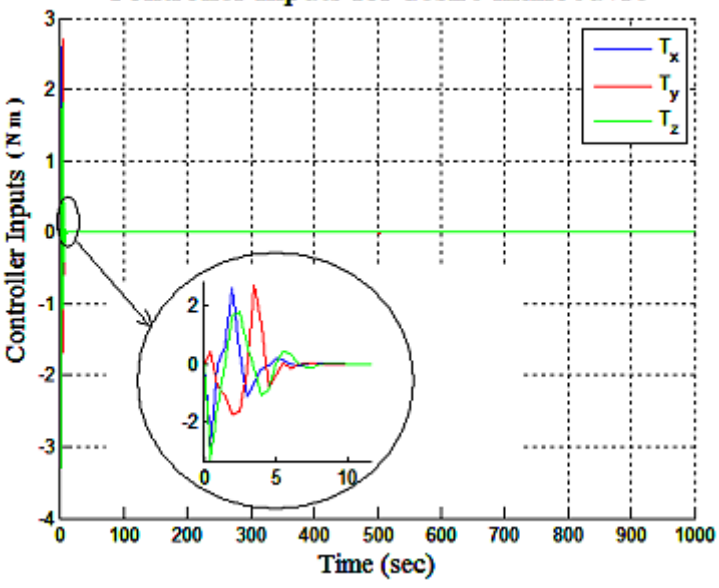

Fig 12: control torques (first approach implementation)

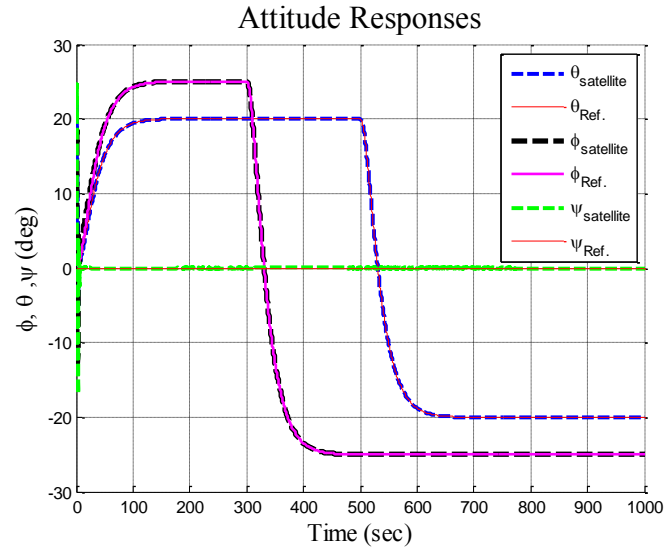

Fig 13: roll, pitch and yaw angles (second approach implementation)

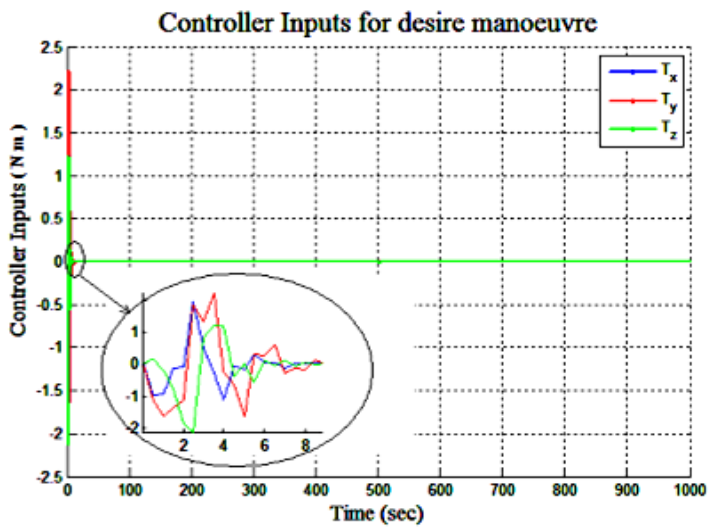

Fig 14: control torques (second approach implementation)

According to figures (5) - (14), Comparing simulation and implementation result show some deviation among these results. The major source of deviation is originated from delay time corresponding to transmission data between on-board electronic and simulator computer. Note that since in real operation in orbit, there is no need to transfer data between the on-board electronic and the computer, so the mentioned error is not problematic. To compared and show these deviations, the mean error $(\operatorname{mean}(e))$, error variance $(\operatorname{var}(e))$ and steady-state error $(E s S)$ for the two proposed approaches are summarized in Table (3)

Table 3. Simulation and implementation results of the two proposed approaches

\begin{tabular}{|c|c|c|c|c|c|c|c|c|c|}
\hline & $\begin{array}{c}\operatorname{var}\left(e_{\psi}\right) \\
\left(\operatorname{deg}^{2}\right)\end{array}$ & $\begin{array}{c}\operatorname{mean}\left(e_{\psi}\right) \\
(\mathrm{deg})\end{array}$ & $\begin{array}{l}E s s_{\psi} \\
(\operatorname{deg})\end{array}$ & $\begin{array}{l}\operatorname{var}\left(e_{\phi}\right) \\
\left(\operatorname{deg}^{2}\right)\end{array}$ & $\begin{array}{l}\operatorname{mean}\left(e_{\phi}\right) \\
(\mathrm{deg})\end{array}$ & $\begin{array}{l}E s s_{\phi} \\
(\mathrm{deg})\end{array}$ & $\begin{array}{l}\operatorname{var}\left(e_{\theta}\right) \\
\left(\operatorname{deg}^{2}\right)\end{array}$ & $\begin{array}{l}\operatorname{mean}\left(e_{\theta}\right) \\
(\mathrm{deg})\end{array}$ & $\begin{array}{l}E s s_{\theta} \\
(\mathrm{deg})\end{array}$ \\
\hline $\begin{array}{l}\text { First approach } \\
\text { simulation }\end{array}$ & 0.549 & $2.325 \mathrm{e}-2$ & $7.615 \mathrm{e}-6$ & 0.250 & $5.635 \mathrm{e}-3$ & $2.699 \mathrm{e}-6$ & 0.190 & $2.256 \mathrm{e}-2$ & $2.387 e-6$ \\
\hline $\begin{array}{l}\text { Second approach } \\
\text { simulation }\end{array}$ & 0.728 & $2.829 \mathrm{e}-2$ & $-1.074 \mathrm{e}-5$ & 0.403 & $2.078 \mathrm{e}-2$ & $-1.594 \mathrm{e}-6$ & 0.591 & $5.404 \mathrm{e}-2$ & $3.663 \mathrm{e}-6$ \\
\hline $\begin{array}{l}\text { First approach } \\
\text { implementation }\end{array}$ & 0.648 & $2.431 \mathrm{e}-2$ & $6.135 \mathrm{e}-5$ & 0.321 & $6.430 \mathrm{e}-3$ & $4.445 \mathrm{e}-5$ & 0.213 & $3.178 \mathrm{e}-2$ & $1.283 \mathrm{e}-5$ \\
\hline $\begin{array}{l}\text { Second approach } \\
\text { implementation }\end{array}$ & 0.818 & $2.983 \mathrm{e}-2$ & $-1.539 e-5$ & 0.524 & $2.608 \mathrm{e}-2$ & $-2.734 e-5$ & 0.681 & $8.128 \mathrm{e}-2$ & $5.293 e-5$ \\
\hline
\end{tabular}

According to the figures (5)-(14) and Table (3), it is obvious that the convergence speed of parameter estimation using the second approach is higher, but it is less accurate than the first approach. These results are compared in table (4) in brief. 
Table 4: comparison results of the two proposed approaches

\begin{tabular}{|c|c|c|}
\hline Index & $\begin{array}{c}\text { Convergence } \\
\text { speed }\end{array}$ & Accuracy \\
\hline First & Low & High \\
\hline Second & High & Low \\
\hline
\end{tabular}

\section{CONCLUSION}

In this paper, a discrete-time model reference adaptive attitude control algorithm (MRAC) designed based on unified approach for a three-axis stabilized satellite. In this algorithm, environmental disturbances and nonlinear dynamic terms estimated as a time-varying unknown parameter. The designed algorithm implemented in software in the loop test bed with the use of ARM microcontroller in real time mode. According to Figures (5)-(14), it can be concluded that the designed control algorithms achieve properly in presence of environmental disturbances and nonlinear dynamic with unknown parameters. The proposed method is capable of simultaneous tracking and regulation and simplicity of implementation and high adaptation speed. The results in Table (3) illustrate that the convergence speed of parameter estimation using the second approach is higher, but it is less accurate than the first approach.

\section{REFERENCES}

[1] Shahravi, M., Kabganian, M., and Alasty, A. 2006. Adaptive robust attitude control of a flexible spacecraft. International Journal of Robust and Nonlinear Control.

[2] Bolandi, H., Saberi, F. F., and Vaghei, B. G. 2010. Design Of A Supervisory Adaptive Attitude Control (SAAC) System For A Stereo-Imagery Satellite Based On Multiple Model Control With Switching. International Journal of Innovative Computing, Information and Control.

[3] Saberi, F. F., Fazlyab, A., and Ajorkar, A. 2014. Design and Implementation of a Sliding Mode Attitude Controller of a Satellite in Software in the Loop Test Bed. International Journal of Computer Applications.

[4] Yoon, H., Tsiotras, P. 2008. Adaptive Spacecraft Attitude Tracking Control with Actuator Uncertainties. Journal of the Astronautical Sciences.
[5] Kunfeng Lu, Yuanqing Xia. 2013. Adaptive attitude tracking control for rigid spacecraft with finite-time convergence. Automatica.

[6] Chalam, V.V. 1987. Adaptive Control Systems Techniques And Applications. Copyright By MARCEL DEKKER.

[7] Cruz, G., Bernstein, D. S. 2013. "Retrospective Cost Adaptive Control of Spacecraft Attitude Using Magnetic Actuators" AIAA Guidance, Navigation, and Control Conference.

[8] LANDAU, I. D., LOZANO, R. 1981. Unification of Discrete Time Explicit Model Reference Adaptive Control Designs. Automatica .

[9] Sidi, M. J. 1997. Spacecraft Dynamic And Control A Practical Engineering Approach. Cambridge University Press.

[10] Schwartz, J. L., Peck, M. A., and Hall C. D. 2003. Historical Review of Air-Bearing Spacecraft Simulators. JOURNAL OF GUIDANCE, CONTROL, AND DYNAMICS Vol. 26, No. 4.

[11] Mittelsteadt, C. O., Mehiel, E. A. 2007. "The cal poly spacecraft attitude dynamics simulator - CP/SADS" in AIAA Guidance, Navigation and Control Conference and Exhibit.

[12] Kabganian, M., Nabipour, M., and Saberi, F. F. 2013. "Modeling and Laboratory Verification of A Three Degree of Freedom Gimbal Simulator" $21^{\text {st }}$ International Conference of Mechanical Engineering, Iran.

[13] Yang, H. C., Sababha, B., Acar, C., and Rawashdeh, O 2010. Rapid Prototyping of Quadrotor Controllers using MATLAB RTW and dsPICs. AIAA 2010-3407.

[14] Lewis, E. K., Vuong, N. D. 2012. "Integration of MATLAB Simulink Models with the Vertical Motion Simulator" AIAA Modeling and Simulation Technologies Conference.

[15] Sanyal, A. K., Lee-Ho, Z. 2009. “Attitude Tracking Control of a Small Satellite in Low Earth Orbit" AIAA Guidance, Navigation, and Control Conference. 